\title{
Association between a New Sugar Index and Caries Experience: Results of a Cross-Sectional Field Study
}

\author{
Klaus Pieper ${ }^{\mathrm{a}} \quad$ Julia Winter ${ }^{\mathrm{a}} \quad$ Monika Heinzel-Gutenbrunner ${ }^{\mathrm{a}}$ \\ Jutta Margraf-Stiksrud ${ }^{b}$

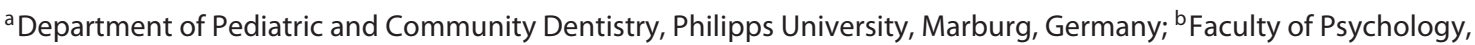 \\ Philipps University, Marburg, Germany
}

\section{Keywords}

Diet · Sugar index · ICDAS · Fourth-graders · Sixth-graders ·

Cross-sectional study · Fissure sealants · Public dental health

\begin{abstract}
Objectives: The aim of this study was to test the relationship between a newly developed sugar index and caries experience in 4th- and 6th-graders. Materials and Methods: A total of 1,019 fourth-graders and 925 sixth-graders from 2 regions in Northern Germany participated in the study. Caries experience was recorded by applying the ICDAS criteria. Tooth-brushing habits and other independent variables were examined psychometrically. Structured questions were formulated that were related to specific everyday eating situations, especially between main meals, which proved to be relevant for a higher caries risk. To compare mean caries scores, nonparametric tests were applied. The Pearson coefficient was calculated in order to verify the correlation between the sugar index and the caries experience. The influence of various independent variables on caries experience was assessed by stepwise backward logistic regression analysis. Results: With regard to the primary teeth of the 4thgraders, significant correlations with values $>0.1$ were found for all ICDAS outcome variables. With regard to the perma-
\end{abstract}

nent teeth of the 6th-graders, the only significant correlations with the sugar index were for the ICDAS outcome variables $\mathrm{D}_{3-6} \mathrm{MFT}$ and $\mathrm{D}_{3-6} \mathrm{FS}$. Conclusion: The results of our study show that not only the correlation between the sugar index and caries experience was stronger for 4th-graders than for 6th-graders, but also more distinctly visible differences were observed when comparing extreme groups. This indicates that protective factors, such as fluoridation and the preventive sealing of fissures, help level out the differences in caries occurrence in older children when compared to younger children.

(C) 2018 The Author(s) Published by S. Karger AG, Basel

\section{Introduction}

As several studies have demonstrated, it is often impossible for clinical studies conducted under "real life" conditions to show a clear connection between sugar intake and the dependent variable of "caries experience" [Burt and Pai, 2001]. Monyihan and Kelly [2014] found clear evidence for the correlation between caries and sug-

This article is based on a contribution to the Joint ORCA-EADPH Symposium on Sugar and Oral Health, July 6, 2016. 
ar intake in their review of studies of a moderately good quality according to GRADE standards. To answer the WHO questions concerning the benefit of a further reduction of sugar intake, i.e., from $<10 \%$ to $<5 \%$ [WHO, $2010,2015]$, they found little evidence for this recommendation because of the small database of only 3 studies. Saido et al. [2016] contributed to answering these questions by collecting data on 5,000 children aged 5-6 years, and found a trend to support the recommendation of a sugar intake of $<5 \%$. To gain further information about correlations between caries experience and even small amounts of sugar intake, more data should be gathered.

The fact that a relationship between sugar intake and caries experience or increment cannot always be demonstrated is not least connected to the major confounder of "fluoridation," which has a strong influence on caries occurrence [Hausen et al., 1981; Bernabé et al., 2016]. Another problem is to accurately survey eating habits in children and adolescents, especially their sugar intake [Chi et al., 2015].

In a study assessing the prevalence of early childhood caries and correlating this parameter to various independent variables, significant associations of feeding practices to $\mathrm{d}_{3+4} \mathrm{mft}$ scores were observed [Pieper et al., 2012]. For example, children who nursed freely from the bottle at night beyond their 8th month of life had almost twice as much caries as children who did not. On the other hand, the differences in caries experience for some independent variables were not significant. This holds for the simple question of the frequency of daily intake of sugary foodstuffs as well as for the question of the frequency of between-meal snacks containing sugar.

When interpreting the nonexistent connection between the reported frequency of sugar intake and the observed caries experience, it should be considered that the factors relating to individual behavior were registered using parents' questionnaires. This could result in a distortion of the parents' responses toward what is socially more desirable.

This is the reason why a more refined questionnairebased investigation method was developed for a later study with schoolchildren [Pieper et al., 2013]. This study had focused on the Marburg model of intensive dental care for 1st- to 6th-grade children. As early as 1981, a preventive program for elementary students had been established in Marburg, based on the application of the fluoride varnish Duraphat ${ }^{\circledR}$. In order to counteract the polarization of caries experience, the basic prevention program in Marburg had been expanded in 1995 to include selective intensive prevention (SIP).

Association between a New Sugar Index and Caries Experience
SIP is offered at individual schools in underprivileged districts and comprises the following measures:

- enhanced health education

- oral hygiene instructions 4 times per year

- fluoride varnish applications 4 times per year.

In addition, the Public Health Service has a nutritionist provide intensive nutritional counseling in the relevant $3 \mathrm{rd}$ and 4 th grade classes (2 lessons of $2 \mathrm{~h}$ each).

To investigate the effectiveness of SIP, the subjects in County Marburg-Biedenkopf (the test group) had been compared to a reference group. In the test region, all schools in socially deprived areas taking part in SIP had been included. For the control group, children from a demographically similar region in Germany (County Osnabrück) had been recruited from schools in comparable areas without intensive prevention measures. All pupils willing to participate had been registered by their parents who also gave their informed consent. Mentally or physically disabled adolescents were not included in the study.

Caries experience as the most important dependent variable had been recorded in 4th- and 6th-graders [Pieper et al., 2013]. Besides dietary habits as the most important independent variable of interest, other factors like a knowledge of dental health, dental health behavior, and attitudes toward prevention had been examined psychometrically. In addition, data on the parents had been gathered for both the test and reference groups.

The study was approved by the ethics committee of the medical faculty of the Philipps University, Marburg (file No. 200/06; chairman: Prof. G. Richter).

Overall, the comparison between the test and the control group showed significant differences in caries experience. Children receiving SIP in Marburg had presented lower dmft scores than children without this special program in Osnabrück.

A detailed presentation of the results of the above study can be found in the final report on the project [Pieper and Margraf-Stiksrud, 2010] which is accessible via the following link: http://edok01.tib.uni-hannover. de/edoks/e01fb11/655839291.pdf.

\section{Aim of the Study}

The aim of this study was to use the data collected in the study mentioned above to examine the relationship between a newly developed sugar index and caries experience in 4th- and 6th-graders. Additionally, we investigated whether the preventive sealing of fissures makes the influence of the diet less relevant. 
The following hypothesis was tested: caries experience (expressed by ICDAS scores) and the newly developed sugar index are significantly correlated in children and adolescents.

\section{Methods}

\section{Study Areas and Population}

Our evaluation is based on the data of 1,019 fourth- and 925 sixth-graders from the 2 regions described above, which were pooled for this analysis.

More detailed information on the study areas and population has already been published [Pieper et al. 2013]. Detailed information on the eligibility criteria and methods of selection of participants can be found in the final report on the project [Pieper and Margraf-Stiksrud, 2010].

\section{Development of the Questionnaire: Psychometric Evaluation}

To assess dietary behaviors, several strategies have been discussed, e.g., 24-h recalls of consumed food, food frequency lists, food diaries, and biological markers as an objective consequence of behavior [Evans et al., 2013; Chi et al., 2015; Llena et al., 2015; Saido et al., 2016]. No gold standard has been established yet, since every method has its strengths and weaknesses, depending on the aim of the study and the data collection [Burt and Pai, 2001; Neuhouser et al., 2009]. For use in complex research designs investigating several variables in large samples, self-administered questionnaires concerning eating habits are economical and appropriate when their measurement qualities are verified.

The aim in developing the new diet questionnaire was to obtain information based on actual behavior concerning eating habits relevant to oral health, a procedure also recommended by Neuhouser et al. [2009]. The questionnaire should be applicable for children in the 4 th and 6th grades in group-specific adaptation, respectively. They should also appeal to different social and cultural groups, to be able to use them in school with all the children in a class.

The construction process included 3 steps:

1. Analysis of the relevant literature and interviews on eating habits of various ethnic and cultural groups, formulating items.

2. Defining the sections of the questionnaire, deciding about the response options and preliminary examination in any of the above groups to assess and analyze the quality of measurements.

3. Revision based on item analysis.

\section{Step 1: Preparing Item Formulation}

The following already available instruments were assessed in detail:

- Augsburg Food Frequency List [Winkler and Döring, 1998]

- Questions about nutrition from the German Oral Health Study [Micheelis and Schroeder, 2006]

- Checklist for the Nutrition Report and Questionnaire on Food Frequency [Stegemann and Davis, 2007]

- KIGGS Study [Mensink et al., 2007].

Step 2: Structuring of the Questionnaire

Structured questions were formulated, e.g., "How often do you eat..." related to specific everyday eating situations, especially be- tween main meals, which proved to be relevant for a higher caries risk. The food items consumed in these situations should contain foods that are harmless and those that are detrimental to dental health (cariogenic). The situations included: (1) breakfast, (2) between-meal snacks, (3) watching television, and (4) eating on the go.

Additionally, 2 of 6 questions were devised to find out what sort of food and beverages were preferred. The frequency of consumption of the provided food items was graduated into 5 options (never, seldom, occasionally, often, and always), which were given point values from 1 to 5 . All checked food and beverages that were tooth-friendly were given a score of 0 points during the processing of the data, regardless of how often they were reportedly consumed.

The other foodstuffs were given the point score listed above. For each situation, item scores were counted as a sum of the point values of the indicated foods.

Item and reliability analysis in the pretest with 94 fourth-graders and 82 sixth-graders, showed satisfying overall reliability (Cronbach's a for the 6 eating situations: 0.71 for 4 th-graders and 0.69 for 6 th-graders). Corrected-item total correlations lay between 0.29 and 0.54 (mean 0.43 ).

\section{Step 3: Revision and Sugar Index}

For further analyses, the sum scores of all accepted items were added to yield the so-called sugar index. This index serves as an indicator of the frequency of mono- and disaccharide intake. The higher the value of the sugar index, the more unfavorable the dietary habits are.

The final version of the questionnaire and a description for calculating the sugar index can be found as online supplementary files 1 and 2 (see www.karger.com/doi/10.1159/000486102 for all online suppl. material).

\section{Dental Examination}

ICDAS II was used to assess the caries experience of the 2 groups [Pitts, 2004; Jablonski-Momeni et al., 2008; Braga et al., 2009]. Since the radiation protection laws are very restrictive in Germany, no radiographs could be taken. Instead, fiberoptic transillumination (FOTI) was applied to facilitate the diagnosis of approximal lesions. The presence of sealants was recorded, also taking into account whether or not these were complete. The examinations in the schools were conducted by 1 examiner specially trained for this purpose. During a presurvey training period, this dentist was calibrated by an experienced senior examiner (K.P). The interexaminer reliability of the recordings ( $\kappa$ value) amounted to 0.74 and the intraexaminer reliability to 0.86 .

The records of the Marburg County Dental Public Health Service were used to investigate which preventive measures had been applied for each individual child during his/her school career. The frequency of oral hygiene instructions, dietary counseling, and topical fluoridation using Duraphat varnish was recorded.

\section{Data Collection and Statistical Analysis}

All data were collected in the school setting, with administration of the questionnaires in the classroom and dental examination individually in a separate room. The findings were recorded on a documentation form during the examination, noting the type of school, gender, and date of examination of the child. A special blank was used for recording the group prevention measures. The 
Table 1. Quantiles of the sugar index for 4th- and 6th-graders

\begin{tabular}{lllllllll}
\hline & Minimum & $\begin{array}{l}\text { 10th } \\
\text { percentile }\end{array}$ & $\begin{array}{l}\text { 25th } \\
\text { percentile }\end{array}$ & Mean & Median & $\begin{array}{l}75 \text { th } \\
\text { percentile }\end{array}$ & $\begin{array}{l}\text { 90th } \\
\text { percentile }\end{array}$ & Maximum \\
\hline 4th-graders & 27 & 41 & 47 & 56.1 & 55 & 63 & 73 & 117 \\
6th-graders & 31 & 44 & 51 & 58.7 & 58 & 66 & 74 & 118 \\
\hline
\end{tabular}

The maximum possible value is 125 .

Table 2. Correlation between the sugar index and different outcome variables characterizing caries experience

\begin{tabular}{lcccccc}
\hline & $\mathrm{d}_{5-6} \mathrm{mft}$ & $\mathrm{d}_{3-6} \mathrm{mft}$ & $\mathrm{d}_{3-6} \mathrm{fs}$ & $\mathrm{D}_{5-6} \mathrm{MFT}$ & $\mathrm{D}_{3-6} \mathrm{MFT}$ & $\mathrm{D}_{3-6} \mathrm{FS}$ \\
\hline $\begin{array}{l}\text { 4th-graders } \\
\quad \text { Spearman's Rho }\end{array}$ & 0.128 & 0.134 & 0.149 & 0.042 & 0.089 & 0.090 \\
$\quad \begin{array}{l}p \text { value } \\
\text { 6th-graders }\end{array}$ & 0.001 & $<0.001$ & $<0.001$ & 0.252 & 0.015 & 0.014 \\
$\quad$ Spearman's Rho & & & & & \\
$\quad p$ value & & & 0.048 & 0.075 & 0.074 \\
$\quad$ & & & 0.186 & 0.040 & 0.045 \\
\hline
\end{tabular}

quality of the electronically recorded data was checked for further editing. More detailed statements on the quality check of the data input can be found in the final report on the project [Pieper and Margraf-Stiksrud, 2010].

The statistical analysis was performed using IBM ${ }^{\circledR}$ SPSS v24. The simultaneous influence of the sugar index, further potential risk factors, and protecting factors was evaluated in a stepwise logistic regression.

Mann-Whitney $\mathrm{U}$ tests were used to test the differences between groups. Spearman correlation coefficients were calculated to evaluate the association of sugar index and caries experience. The significance level was set at $\alpha=0.05$.

\section{Results}

Overall, the data on 1,019 fourth-graders and 925 sixth-graders could be taken into account. The analysis focused on the following independent variables:

- nutrition expressed by sugar index

- the use of fluoridated toothpaste

- fluoride supplements (tablet fluoridation)

- the use of fluoridated table salt

- the application of fluoride varnish in the dental practice

- other fluoride preparations topically applied in the dental practice

- the application of fluoride varnish in schools

- teeth with fissure sealants.

\section{Correlation between Sugar Index and Caries \\ Experience}

For a first overview, the distributions of the sugar index for the 4th-and 6th-graders were inspected. Table 1 shows the figures characterizing these distributions, which were symmetric and had similar means.

In the 4th-graders, between $2.2 \%$ (situation 3 ) and $20.1 \%$ (situation 1) mentioned further items that they ate. The mean for the 6 situations amounted to 7.3. The corresponding values for the 6th-graders were 2.7 (situation 6) and 12.2 (situation 3 ), with a mean of 5.8 .

Table 2 shows the correlation between sugar index and different outcome variables for the 2 age groups.

\section{Fourth-Graders}

With regard to primary teeth, significant correlations with values $>0.1$ were found for all ICDAS outcome variables, although these values do not represent a very strong correlation. Permanent teeth also showed a significant correlation, but not with regard to all outcome variables. The comparison between 2 extreme groups for a more detailed analysis of the correlations yielded interesting results (Table 3 ). Here, the $10 \%$ of children with the lowest sugar index (scores $<10$ th percentile) were compared to the $10 \%$ with the highest sugar index (scores $>90$ th percentile). The mean values for certain ICDAS combinations were twice as high in the group with the highest 
Table 3. Comparison of caries experience of extreme groups: 4th- and 6th-graders with a sugar index $<10$ th percentile and $>90$ th percentile

\begin{tabular}{lllllll}
\hline & $\mathrm{d}_{5-6} \mathrm{mft}$ & $\mathrm{d}_{3-6} \mathrm{mft}$ & $\mathrm{d}_{3-6} \mathrm{fs}$ & $\mathrm{D}_{5-6} \mathrm{MFT}$ & $\mathrm{D}_{3-6} \mathrm{MFT}$ & $\mathrm{D}_{3-6} \mathrm{FS}$ \\
\hline 4th-graders & & & & & & \\
$\quad$ <10th percentile & 0.9 & 1.51 & 1.79 & 0.4 & 0.86 & 0.94 \\
$\quad$ >90th percentile & 1.66 & 2.78 & 3.82 & 0.6 & 1.43 & 1.7 \\
$\quad p$ value & 0.003 & $<0.001$ & 0.001 & 0.131 & $<0.01$ & 0.009 \\
$\begin{array}{l}\text { 6th-graders } \\
\quad \text { 10th percentile }\end{array}$ & & & & & & \\
$\quad$ >90th percentile & & & & 0.81 & 1.54 & 1.75 \\
$\quad p$ value & & & & 0.89 & 1.99 & 2.14 \\
$\quad$ & & & & 0.26 & 0.054 & 0.069 \\
\hline
\end{tabular}

Table 4. Proportion of students who participated temporarily in specific fluoridation measures

\begin{tabular}{|c|c|c|c|c|c|c|c|c|c|c|c|c|c|c|}
\hline & \multicolumn{8}{|c|}{ Fluoride usage at home } & \multicolumn{4}{|c|}{$\begin{array}{l}\text { Topical fluoride application } \\
\text { at the dental practice }\end{array}$} & \multirow{2}{*}{\multicolumn{2}{|c|}{$\begin{array}{l}\text { Fluoride application } \\
\text { at school }\end{array}$}} \\
\hline & \multicolumn{2}{|c|}{ toothpaste } & \multicolumn{2}{|c|}{ tablets } & \multicolumn{2}{|c|}{ table salt } & \multicolumn{2}{|l|}{ gel } & \multicolumn{2}{|c|}{ varnish } & \multicolumn{2}{|c|}{ solution } & & \\
\hline \multicolumn{15}{|l|}{ 4th-graders } \\
\hline No & 3.4 & 35 & 11.7 & 119 & 32.6 & 332 & 46.3 & 472 & 55.2 & 562 & 77.4 & 789 & 78.4 & 220 \\
\hline \multicolumn{15}{|l|}{ 6th-graders } \\
\hline No & 2.1 & 19 & 13.0 & 120 & 38.5 & 357 & 46.9 & 434 & 53.5 & 495 & 78.8 & 740 & 75.1 & 695 \\
\hline Yes & 83.6 & 775 & 77.8 & 720 & 53.0 & 491 & 40.4 & 374 & 42.9 & 397 & 17.5 & 152 & 23.7 & 219 \\
\hline $\begin{array}{l}\text { Missing } \\
\text { information }\end{array}$ & 14.3 & 132 & 9.2 & 86 & 8.5 & 78 & 12.7 & 118 & 3.6 & 34 & 3.7 & 34 & 1.2 & 11 \\
\hline
\end{tabular}

sugar consumption than in the group with the lowest sugar consumption.

\section{Sixth-Graders}

With regard to permanent teeth, the only significant correlations with the sugar index were for the ICDAS outcome variables $\mathrm{D}_{3-6} \mathrm{MFT}$ and $\mathrm{D}_{3-6} \mathrm{FS}$ (Table 2). This correlation was weaker than for the primary teeth of the 4 thgraders. The results of the comparison between the extreme groups point in the same direction (Table 3).

\section{Application of Fluorides}

Table 4 shows the results of the data collection on the application of fluorides: $85.4 \%$ of the 4 th-graders had been using a fluoridated toothpaste for several years, and the corresponding percentage for the 6th-graders was $83.6 \%$. Table 4 demonstrates the distribution of responses for all potential fluoridation measures.
As the stepwise backward logistic regression analysis shows, 4 independent variables were included in the final model (Table 5):

1. Total number of fluoride varnish applications.

2. Sum of teeth with fissure sealants.

3. Sugar index.

4. Start of toothbrushing after the 12th month of life.

The table clearly illustrates that the sugar index is the second most important variable, after the number of sealed teeth, with regard to the presence of caries.

Table 6 shows the influence of preventive fissure sealing on the correlation between sugar index and caries experience in the 2 age groups. Regarding fissure sealing, the correlations in both age groups are only significant in the children without sealed teeth. This indicates a moderation of fissure sealing on the association of sugar index and caries experience. 
Table 5. Association between independent variables and the dependent variable $\mathrm{D}_{3-6} \mathrm{MFT}$ in 6th-graders using a binary logistic backward stepwise regression analysis: final model

\begin{tabular}{llllll}
\hline Independent variables & $\beta$ & SE & $\begin{array}{l}\text { Wald } \\
\text { statistic }\end{array}$ & $p$ value & OR (95\% CI) \\
\hline Number of fluoride varnish applications & -0.045 & 0.027 & 2.900 & 0.089 & $0.956(0.907-1.007)$ \\
Number of sealed teeth & -0.155 & 0.068 & 5.173 & 0.023 & $0.856(0.749-0.979)$ \\
Sugar index & 0.030 & 0.014 & 4.327 & 0.038 & $1.030(1.002-1.059)$ \\
Start of toothbrushing after 12 months of age & 0.330 & 0.186 & 3.153 & 0.076 & $1.391(0.966-2.002)$ \\
\hline
\end{tabular}

$\beta$, adjusted coefficient of the regression; SE, standard error; OR, odds ratio; CI, confidence interval.

Table 6. Correlation between the sugar index and different outcome variables characterizing caries experience for children with and without fissure sealants

\begin{tabular}{|c|c|c|c|c|c|c|}
\hline & \multicolumn{3}{|c|}{ Children without fissure sealants } & \multicolumn{3}{|c|}{ Children with fissure sealants } \\
\hline & $\mathrm{D}_{5-6} \mathrm{MFT}$ & $\mathrm{D}_{3-6} \mathrm{MFT}$ & $\mathrm{D}_{3-6} \mathrm{MFS}$ & $\mathrm{D}_{5-6} \mathrm{MFT}$ & $\mathrm{D}_{3-6} \mathrm{MFT}$ & $\mathrm{D}_{3-6} \mathrm{MFS}$ \\
\hline \multicolumn{7}{|l|}{ 4th-graders } \\
\hline Spearman’s Rho & 0.08 & 0.159 & 0.151 & 0.019 & 0.085 & 0066 \\
\hline$p$ value & 0.239 & 0.019 & 0.027 & 0.674 & 0.057 & 0.139 \\
\hline \multicolumn{7}{|l|}{ 6th-graders } \\
\hline Spearman's Rho & 0.202 & 0.275 & 0.185 & 0.016 & 0.042 & 0.018 \\
\hline$p$ value & 0.004 & $<0.001$ & 0.009 & 0.717 & 0.344 & 0.686 \\
\hline
\end{tabular}

\section{Discussion}

In this study, significant correlations between caries experience in deciduous teeth and sugar intake were found in 4th-graders. This result can be explained by the fact that the occurrence of caries in primary teeth is more strongly affected by the diet provided by the parents and less by confounders such as fluoridation or preventive fissure sealing.

Regarding the permanent teeth of the 6th-graders, significant correlations were found only for the outcome variables $\mathrm{D}_{3-6} \mathrm{MFT}$ and $\mathrm{D}_{3-6} \mathrm{FS}$. Therefore, our data support the main hypothesis. If the influence of diet on outcome variables relevant to caries in permanent teeth is less visible among adolescents, this could be seen as a sign of the success of efforts to prevent dental diseases by means of specific school programs and the preventive measures applied in private practice.

One should also consider the question of how dentists can use the new sugar index to advise their patients about the control of sugar intake. As stated above, the questionnaire relates to nutritional behavior in everyday situa- tions. In the individual counseling situation, this provides a good basis for explaining to the patient where his current nutritional risks lie. Regarding risk size, the patients could be advised to reduce their sugar index to a value below the median $(<55$ for 4 th-graders and $<58$ for 6 thgraders) or a value $<10$ th quantile $(<41$ for 4 th-graders and $<44$ for 6th-graders) if they want to make a greater contribution to prevention by reducing their sugar intake.

The particular effect of preventive fissure sealing is presumably due to the fact that the caries increment in elementary school students with a low and moderate caries risk mainly occurs in the fissures of the first permanent molars. These teeth can be protected to a large extent by preventive fissure sealing [Ahovuo-Saloranta et al., 2013].

The comparatively small correlations between sugar intake and caries experience emphasize the importance of other factors relevant for oral health in the studied age groups. However, we could prove the significant influence of the diet, especially in younger children and in children without preventive fissure sealing, in contrast to 
other studies [Burt and Pai, 2001]. One possible explanation is the use of self-reported dietary behavior of the children themselves and not by asking their parents [Hinnig et al., 2014].

The results of our study show that, not only was the correlation between the sugar index and caries experience stronger in 4th-graders than in 6th-graders, but more distinctly visible differences in the comparison of the extreme groups were also observed.

We judge this as indicating that protective factors, such as fluoridation and the preventive sealing of fissures, help level out the differences in caries occurrence that is a consequence of sugar intake with increasing age. These results are in agreement with the findings of Bernabé et al. [2016] in an adult population. This primarily applies to risks arising from unfavorable eating habits. In this context, the question arises as to whether this leveling of differences functions equally well in all health care systems.

Even though a questionnaire with nearly 100 items (covering the abovementioned psychological variables) used in our study of the Marburg SIP is a relatively complex psychometric instrument, the diet portion of the questionnaire is short (6 situations) and simple in its application. The children in our study showed a good acceptance of the questionnaire. The reported characteristics of the items and the sugar index meet the quality criteria for reliable measurement and can claim content validity. The data obtained from the questionnaire gave a good depiction of eating habits relevant to dental health, as the correlation with caries experience shows.

According to Chaffee et al. [2015] and Mensink et al. [2007], useful dietary information has to be directed to the aim of the study context. To assess the quality of food intake in general, other types of information are necessary to investigate correlations between diet and obesity, or, as in the context that was relevant in this study, oral health. Therefore, the confirmation of our hypothesis may also be a consequence of the adequate selection of oral health-related eating situations and food items. Otherwise, the usual discrepancy between reported dietary behavior and the food that is actually consumed in everyday life has to be taken into account. This could also have contributed to the relatively low correlations in our data. However, no test-retest reliability information could be gathered yet, and validation of the criteria with other questionnaires or food diaries must be proved by further studies. This can count as a limitation for the generalizability of our results.

\section{Conclusion}

On the basis of our results, it may be hypothesized that there are great differences in the correlation between sugar index and caries experience/increment, depending on the extent to which social security and health care systems pay for preventive measures (e.g., the preventive sealing of molars) and whether effective interventions, such as fluoride varnish applications, are performed in schools.

In Germany, the situation in this regard appears to be comparatively favorable, since all children, from the age of 6 years, have free access both to fissure sealants and topical fluoride applications [Pieper and Schulte, 2004; Schulte et al., 2006].

\section{Acknowledgements}

This study was supported by the German Federal Government (grant No. BMBF 01EL0617).

\section{Disclosure Statement}

The authors declare no potential conflict of interest with respect to the publication of this article.

\section{Author Contributions}

K.P.: conception and implementation of study, training of examiners, management of data collection, interpretation of data, drafting and revision of manuscript. J.W.: interpretation of data, initial drafting and revision of manuscript. M.H.-G.: data analysis. J.M.-S.: conception and implementation of study, data analysis, interpretation of data, drafting and revision of manuscript.

References

Ahovuo-Saloranta A, Forss H, Walsh T, Hiiri A, Nordblad A, Mäkelä M, Worthington HV: Sealants for preventing dental decay in the permanent teeth. Cochrane Database Syst Rev 2013;28:CD001830.

Bernabé E, Vehkalahti MM, Sheiham A, Lundquist A: The shape of the dose-response relationship between sugars and caries in adults. J Dent Res 2016;95:167-172.

Braga MM, Oliveira LB, Bonini GA, Bönecker M, Mendes FM: Feasibility of the International Caries Detection and Assessment System (ICDAS-II) in epidemiological surveys and comparability with standard World Health Organization criteria. Caries Res 2009;43:245-249. 
Burt BA, Pai S: Sugar consumption and caries risk: a systematic review. J Dent Educ 2001;65: 2017-2023.

Chaffee BW, Feldens CA, Rodrigues PH, Vítolo MR: Feeding practices in infancy associated with caries incidence in early childhood. Community Dent Oral Epidemiol 2015;43:338-348.

Chi DL, Hopkins S, O’Brien D, Mancl L, Orr E, Lenaker D: Association between added sugar intake and dental caries in Yup'ik children using a novel hair biomarker. BMC Oral Health 2015; 15:121.

Evans EW, Hayes C, Palmer CA, Bermudez OI, Cohen SA, Must A: Dietary intake and severe early childhood caries in low-income, young children. J Acad Nutr Diet 2013;113:10571061.

Hausen $\mathrm{H}$, Heinonen OP, Paunio I: Modification of occurrence of caries in children by toothbrushing and sugar exposure in fluoridated and nonfluoridated areas. Community Dent Oral Epidemiol 1981;9:103-107.

Hinnig Pde F, Mariath AB, Freaza SR, Gambardella AM, Bergamaschi DP: Development of a food frequency questionnaire for children from 7 to 10 years old. Rev Bras Epidemiol 2014;17:479-494.

Jablonski-Momeni A, Stachniss V, Ricketts DNJ, Heinzel-Gutenbrunner M, Pieper K: Reproducibility and accuracy of the ICDAS-II for detection of occlusal caries in vitro. Caries Res 2008;42:79-87.

Llena C, Leyda A, Forner L, Garcet S: Association between the number of early craious lesions and diet in children with a high prevalence of caries. Eur J Paediatr Dent 2015;16: $7-12$.
Mensink GBM, Bauch A, Vohmann C, Stahl A, Six J, Kohler S, Fischer J, Heseker H: EsKiMo - Das Ernährungsmodul im Kinder- und Jugendgesundheitssurvey (KiGGS). Bundesgesundheitsblatt - Gesundheitsforschung Gesundheitsschutz 2007;50;902-908.

Micheelis W, Schroeder E: Aufbau der sozialwissenschaftlichen Erhebungsinstrumente; in Micheelis W, Schiffner U (eds): Vierte Deutsche Mundgesundheitsstudie (DMS IV). Neue Ergebnisse zu oralen Erkrankungsprävalenzen, Risikogruppen und zum zahnärztlichen Versorgungsgrad in Deutschland 2005. Köln, Deutscher Zahnärzte, 2006, pp 129-192.

Moynihan PJ, Kelly SAM: Effect on caries of restricting sugars intake: systematic review to inform WHO guidelines. J Dent Res 2014;93: 8-18.

Neuhouser ML, Lilley S, Lund A, Johnson DB: Development and validation of a beverage and snack questionnaire for use in evaluation of school nutrition policies. J Am Diet Assoc 2009; 109:1587-1592.

Pieper K, Dressler S, Heinzel-Gutenbrunner M, Neuhäuser A, Krecker M, Wunderlich K, Jablonski-Momeni A: The influence of social status on pre-school children's eating habits, caries experience and caries prevention behavior. Int J Public Health 2012;57 207-215.

Pieper K, Margraf-Stiksrud J: Evaluation und Optimierung eines zahnmedizinischen Präventionsprogramms für Kinder mit erhöhtem Kariesrisiko - Abschlussbericht (FKZ: 01EL0617), Marburg, 2010. http://edok01.tib. uni-hannover.de/edoks/e01fb11/655839291. pdf.
Pieper K, Schulte AG: The decline in dental caries among 12-year-old children in Germany between 1994 and 2000. Community Dent Health 2004;21:199-206.

Pieper K, Weber K, Margraf-Stiksrud J, HeinzelGutenbrunner M, Stein S, Jablonski-Momeni A: Evaluation of a preventive program aiming at children with increased caries risk using ICDAS II criteria. Clin Oral Investig 2013;17: 2049-2055.

Pitts NB: An international system for caries detection and assessment being developed to facilitate caries epidemiology and appropriate clinical management. Community Dent Health 2004;21:193-198.

Saido M, Asakura K, Masayasu S, Sasaki S: Relationship between dietary sugar intake and dental caries among Japanese preschool children with relatively low sugar intake (Japan Nursery School SHOKUIKU study): a nationwide cross-sectional study. Matern Child Health J 2016;20:556-566.

Schulte AG, Momeni A, Pieper K: Caries prevalence in 12-year-old children from Germany. Results of the 2004 national survey. Community Dent Health 2006;23:197-202.

Stegemann CA, Davis JR: Zahnmedizin und Ernährung. München, Elsevier 2007.

WHO: Handbook for Guideline Development, 2010. www.who.int/hiv/topics/mtct/grc handbook_mar2010_1.pdf (URL accessed on 9/24/2013).

WHO: Guideline: Sugar Intake for Adults and Children. Geneva, 2015.

Winkler G, Döring A: Validation of a short qualitative food frequency list used in several German large scale surveys. Z Ernaehrungswiss 1998;37:234-241. 